\title{
Nevus of Ota
}

National Cancer Institute

\section{Source}

National Cancer Institute. Nevus of Ota. NCI Thesaurus. Code C7583.

A brown, blue, or gray hamartoma of dermal melanocytes, usually on the skin of the face along the distribution of the ophthalmic and maxillary branches of the trigeminal nerve that is most commonly found in Asian populations and in females and is usually benign. It may also involve the oral or ocular mucosal surfaces, and periosteum. 